\title{
Suboptimal blood pressure control in chronic kidney disease stage 3: baseline data from a cohort study in primary care
}

Simon DS Fraser ${ }^{1 *}$, Paul J Roderick ${ }^{1}$, Natasha J Mcintyre ${ }^{2}$, Scott Harris ${ }^{1}$, Christopher W Mcintyre ${ }^{3}$, Richard J Fluck ${ }^{2}$ and Maarten W Taal ${ }^{2}$

\begin{abstract}
Background: Poorly controlled hypertension is independently associated with mortality, cardiovascular risk and disease progression in chronic kidney disease (CKD). In the UK, CKD stage 3 is principally managed in primary care, including blood pressure (BP) management. Controlling BP is key to improving outcomes in CKD. This study aimed to investigate associations of BP control in people with CKD stage 3.
\end{abstract}

Methods: 1,741 patients with CKD 3 recruited from 32 general practices for the Renal Risk in Derby Study underwent medical history, clinical assessment and biochemistry testing. BP control was assessed by three standards: National Institute for Health and Clinical Excellence (NICE), National Kidney Foundation Kidney Disease Outcome Quality Initiative (KDOQI) and Kidney Disease: Improving Global Outcomes (KDIGO) guidelines. Descriptive statistics were used to compare characteristics of people achieving and not achieving BP control. Univariate and multivariate logistic regression was used to identify factors associated with BP control.

Results: The prevalence of hypertension was 88\%. Among people with hypertension, 829/1426 (58.1\%) achieved NICE BP targets, 512/1426 (35.9\%) KDOQI targets and 859/1426 (60.2\%) KDIGO targets. Smaller proportions of people with diabetes and/or albuminuria achieved hypertension targets. 615/1426 (43.1\%) were only taking one antihypertensive agent. On multivariable analysis, BP control (NICE and KDIGO) was negatively associated with age (NICE odds ratio (OR) 0.27; 95\% confidence interval (95\% Cl) 0.17-0.43) 70-79 compared to <60), diabetes (OR 0.32; $95 \% \mathrm{Cl} 0.25-0.43)$ ), and albuminuria (OR 0.56; $95 \% \mathrm{Cl} 0.42-0.74)$ ). For the $\mathrm{KDOQ}$ target, there was also association with males (OR 0.76; 95\% Cl 0.60-0.96)) but not diabetes (target not diabetes specific). Older people were less likely to achieve systolic targets (NICE target OR $0.17(95 \% \mathrm{Cl} 0.09,0.32) \mathrm{p}<0.001)$ and more likely to achieve diastolic targets $(\mathrm{OR} 2.35(95 \% \mathrm{Cl} 1.11,4.96) \mathrm{p}<0.001)$ for people $>80$ compared to < 60).

Conclusions: Suboptimal BP control was common in CKD patients with hypertension in this study, particularly those at highest risk of adverse outcomes due to diabetes and or albuminuria. This study suggests there is scope for improving BP control in people with CKD by using more antihypertensive agents in combination while considering issues of adherence and potential side effects.

Keywords: Chronic kidney disease, Hypertension, Blood pressure control, Albuminuria, Diabetes, Primary care

\footnotetext{
* Correspondence: s.fraser@soton.ac.uk

'Academic Unit of Primary Care and Population Sciences, Faculty of Medicine, University of Southampton, South Academic Block, Southampton General Hospital, Tremona Road, Southampton, Hampshire SO16 6YD, UK Full list of author information is available at the end of the article
} 


\section{Background}

People with chronic kidney disease (CKD) are at increased risk of mortality, cardiovascular disease (CVD) and less commonly progression to end stage kidney disease (ESKD) [1,2]. Uncontrolled hypertension, albuminuria, and diabetes are independent risk factors for these adverse outcomes [3-8]. Hypertension is common in CKD, with estimates of prevalence between $60 \%$ and $92 \%$ in stage 3 [9-12]. Control of hypertension is arguably the most important intervention for reducing the increased risk of cardiovascular disease in people with $\mathrm{CKD}$, and to slow progression to later stages of CKD $[1,11-14]$. However, there is evidence that optimum levels of blood pressure (BP) control are often not achieved among people with CKD, with consistent achievement of BP less than 140/90 observed in between 15 and 30\% of patients (with as few as 13\% achieving a 130/80 threshold) [15-17].

In the UK (as in many countries) early stages of CKD are principally managed in primary care. Several national and international guidelines recommend targets for optimal BP control in people with CKD but there are differences between them, including variation of the targets for those at higher risk of outcome (such as people with diabetes and albuminuria). In the UK there are National Institute for Health and Clinical Excellence (NICE) guidelines on the monitoring and management of CKD, and, in England, incentivised disease management targets from the primary care Quality and Outcomes Framework (QOF) [18,19]. NICE CKD guidelines set a BP control at target $<140 / 90 \mathrm{~mm} \mathrm{Hg}$ for most people with CKD or $<130 / 80$ in people with diabetes or high levels of albuminuria (ACR $>70 \mathrm{mg} / \mathrm{mmol}$ ), while the QOF CKD BP target is $\leq 140 / 85$ [19,20]. In the US, the National Kidney Foundation Kidney Disease Outcome Quality Initiative (NKF KDOQI) guidelines set a BP control target at $<130 / 80$ for all people with CKD [21]. The 2012 Kidney Disease: Improving Global Outcomes (KDIGO) guidelines for the management of blood pressure in CKD recommend that both diabetic and non-diabetic people with non-dialysis dependeant CKD with hypertension but without albuminuria should have BP controlled $\leq 140 / 90$, and people with significant albuminuria (microalbuminuria or macroalbuminuria) with or without diabetes should control $\mathrm{BP} \leq 130 / 80$ [22].

Little is known about CKD-related hypertension control in primary care, particularly in individuals at higher risk, such as those with and without diabetes or albuminuria. In England QOF data are aggregated at practice level and do not allow for interpretation at individual level [23]. This study aimed to evaluate the factors associated with blood pressure control in a population of people with CKD stage 3 in primary care in the UK.

\section{Methods}

\section{Participants and recruitment}

Participants were recruited as part of the Renal Risk in Derby (RRID) study, a prospective cohort study of people with CKD stage 3 in a primary care setting. The methods for the RRID study have been published in detail elsewhere [24]. In summary, eligible participants were 18 years or over, met the Kidney Disease Outcomes Quality Initiative criteria for CKD stage 3 (estimated GFR [eGFR] of between 30 to $59 \mathrm{ml} / \mathrm{min}$ per $1.73 \mathrm{~m}^{2}$ on two or more occasions at least 3 months apart prior to recruitment), were able to give informed consent, and were able to attend their general practitioner (GP) surgery for assessments. People who had previously had a solid organ transplant or who were terminally ill (expected survival $<1$ years) were excluded. The RRID study is conducted by a single nephrology department, but participants were recruited directly from 32 GP surgeries. Eligible patients were invited to participate via a letter sent by their GP and telephoned the coordinating centre to schedule a study visit. Study visits were conducted at participating GP surgeries by the researchers.

\section{Data collection}

First study visits were conducted from August 2008 to March 2010. Screening and baseline visits were combined due to the large proportion of elderly participants and the logistical challenges associated with conducting study visits in multiple primary care centres. Participants were sent a medical and dietary questionnaire as well as three urine specimen bottles, and were asked not to eat cooked meat for at least 12 hours before the assessment. Urine was collected as three early morning samples. Socioeconomic status (SES) was defined by two methods. First, using the Indices of Multiple Deprivation score (IMD); a social deprivation score comprising a composite measure of seven domains which demonstrates a strong relationship to health in all geographical locations [25]. Second, selfreported education status was collected; an important indicator of socioeconomic status in elderly populations [26]. Education status was categorised into eight groups (no formal qualifications, General certificate of Secondary Education (GCSE) or equivalent, Advanced level (A level), National Vocational Qualification (NVQ) 1-3, NVQ 4-5, first degree, higher degree, patient refused to answer), subsequently grouped into three for the purposes of analysis (group one: no formal qualifications, group two: GCSE or equivalent, A level, or NVQ 1-3, group three: first or higher degree, NVQ 4-5). Self-reported ethnicity information was collected, but due to the small number of nonwhite participants in this study, it was categorized into 'White' and 'Other' for the purposes of analysis.

At the assessment, information on questionnaires was checked, anthropomorphic measurements taken, and 
urinalysis performed. Blood specimens were taken and the three urine specimens were submitted for biochemical analysis. eGFR was calculated using the modified 4variable Modified Diet in Renal Disease equation and categorised into four groups $(>60,45-59,30-44,<30)$ [27]. Albuminuria was defined as albumin/creatinine ratio $(A C R) \geq 2.5 \mathrm{mg} / \mathrm{mmol}$ in men $\geq 3.5 \mathrm{mg} / \mathrm{mmol}$ in women in at least two of the three urine specimens ( $\geq 3 \mathrm{mg} / \mathrm{mmol}$ in all people for the KDIGO guideline analyses). BMI was calculated from weight in $\mathrm{kg}$ divided by height squared in metres and categorised according to World Health Organization (WHO) categories underweight $\left(<18.5 \mathrm{~kg} / \mathrm{m}^{2}\right)$, normal $\left(18.5-<25 \mathrm{~kg} / \mathrm{m}^{2}\right)$, overweight $\left(25-<30 \mathrm{~kg} / \mathrm{m}^{2}\right)$, and obese $\left(>=30 \mathrm{~kg} / \mathrm{m}^{2}\right)$ [28]. Central obesity was defined as a waist to hip ratio of $\geq 0.9$ for men or $\geq 0.8$ for women [29]. Diabetes was defined by having a previous clinical diagnosis in line with WHO criteria [30]. Previous cardiovascular event was defined as subject-reported myocardial infarction, stroke, transient ischemic attack, revascularization, or amputation due to peripheral vascular disease, or aortic aneurysm. Smoking status was categorized as never smoked, ex-smoker, and current smoker. Self-reported alcohol consumption was categorized by units per week as never drinking alcohol, drinking within recommended limits $(<21$ units for women, $<28$ units for men), and drinking above recommended limits. Blood pressure was measured after a minimum of five minutes rest in the sitting position, using a validated oscillometric device, recommended by the British Hypertension Society (Digital Blood Pressure Monitor Model UA-767, A\&D Instruments Ltd, Abingdon, UK). The same device was used for all readings. BP was calculated as the mean of three readings that differed by $<10 \%$. Mean arterial pressure (MAP) was calculated as $1 / 3$ the average SBP plus $2 / 3$ the average DBP.

For the purposes of analysis, hypertension was defined as current antihypertensive medication, but those with a systolic BP $>140 \mathrm{mmHg}$ or diastolic BP $>90 \mathrm{mmHg}$ at baseline who were not on medication were also identified for descriptive purposes [31]. Target BP threshold was defined according to three clinical guidelines: the UK NICE guidelines BP target $(<140 / 90$ or $<130 / 80$ in people with diabetes and people with ACR $>70 \mathrm{mg} / \mathrm{mmol}$ ), the US NKF KDOQI guidelines BP target $(<130 / 80$ for all people with CKD), and the KDIGO guidelines $(\leq 140 / 90$ or $130 / 80$ in people with albuminuria) $[19,21,22]$.

Participants were asked 'Were you told that you may have an issue with your kidneys before you were contacted to take part in this study?' Those answering 'yes' were defined as being aware of their CKD diagnosis. The study was approved by the Nottingham Research Ethics Committee 1. All participants provided written informed consent. The study was included on the National Institute for Health Research (NIHR) Clinical Research Portfolio (NIHR
Study ID:6632) and was independently audited by QED Clinical Services in November 2009.

\section{Statistical analyses}

In the population of people with hypertension on antihypertensive medication, standard descriptive statistics were used to compare the characteristics of people achieving and not achieving BP control by NICE, KDOQI, and KDIGO BP targets. Univariate and multivariable logistic regression (adjusting for age, sex, albuminuria, diabetes, CVD, and eGFR) was used to identify the factors associated with achievement of the three BP targets. A model excluding CVD was also constructed to assess the effect of this variable on outcomes in view of the potential for CVD to cause lower BP through heart failure. Sensitivity analyses were conducted in participants whose baseline eGFR was $<60 \mathrm{ml} / \mathrm{min} / 1.73 \mathrm{~m}^{2}$. The logistic regression analyses were also repeated to examine the associations of people achieving NICE systolic and diastolic targets separately. Interaction terms were introduced for gender by diabetes, age by diabetes, and diabetes by albuminuria because of the effect modification seen among these variables in some studies [32]. Chi squared test for trend was used to examine the degree of BP control by grade of albuminuria in people with and without diabetes. For people on antihypertensive medication or those with elevated $B P$ identified at study registration, multivariable linear regression was used to investigate the association between number of antihypertensive medications and MAP. All odds ratios are presented with $95 \%$ confidence intervals (CIs) and p values $<0.05$ are considered statistically significant. IBM SPSS Statistics for Windows version 19 was used to analyse the data.

\section{Results}

\section{Study population}

$22 \%$ (1741) of approximately 8280 eligible participants from 32 GP practices invited to be included in the study agreed to participate (range $8-34 \%$ in different GP practices) and attended baseline assessment. Mean eGFR was $52.5 \mathrm{~mL} / \mathrm{min} / 1.73 \mathrm{~m}^{2}$ (SD 10.4). 418 (24\%) people had eGFR $\geq 60$ at baseline assessment. 280 (16.1\%) had albuminuria on two of three ACR measures. 1426 (81.9\%) were taking antihypertensive medication and a further 102 (5.9\%) had high BP at study assessment (Table 1). See Additional file 1: Table S1 for characteristics of people with and without hypertension.

\section{Antihypertensive treatment}

In those taking antihypertensive medication, reninangiotensin aldosterone system inhibitors (RAASi) were the most commonly used (78.8\% of patients). Of those on antihypertensives, 85/98 (86.7\%) people who met the NICE CKD criteria for requiring RAASi (diabetes with any 
Table 1 Characteristics of people in the RRID study

\begin{tabular}{|c|c|c|}
\hline & Category & $\begin{array}{c}\text { Total } n=1741 \text { (numbers are } n(\% \text { of total) } \\
\text { unless otherwise stated) }\end{array}$ \\
\hline \multirow{2}{*}{ Gender } & Male & $689(39.6 \%)$ \\
\hline & Female & $1052(60.4 \%)$ \\
\hline \multirow{4}{*}{ Age } & $<60$ & $128(7.4 \%)$ \\
\hline & $60-69$ & $445(25.6 \%)$ \\
\hline & $70-79$ & $761(43.7 \%)$ \\
\hline & $80+$ & $407(23.4 \%)$ \\
\hline \multirow{2}{*}{ Ethnicity } & White & $1698(97.5 \%)$ \\
\hline & Other & $43(2.5 \%)$ \\
\hline \multirow{5}{*}{ Index of multiple deprivation } & Quintile 1 (most deprived) & $151(8.7 \%)$ \\
\hline & Quintile 2 & $432(24.8 \%)$ \\
\hline & Quintile 3 & $326(18.7 \%)$ \\
\hline & Quintile 4 & $447(25.7 \%)$ \\
\hline & Quintile 5 (least deprived) & $382(21.9 \%)$ \\
\hline \multirow{3}{*}{ Education status } & Group1 (No formal qualifications) & $953(54.7 \%)$ \\
\hline & Group 2 (GCSE, Alevel, NVQ 1-3) & $469(26.9 \%)$ \\
\hline & Group 3 (1st or higher degree, NVQ 4-5) & $317(18.2 \%)$ \\
\hline \multirow{5}{*}{ eGFR at study entry } & Mean (SD) & $52.5(10.4)$ \\
\hline & $>60$ & $418(24.0 \%)$ \\
\hline & $45-59$ & $911(52.3 \%)$ \\
\hline & $30-44$ & $386(22.2 \%)$ \\
\hline & $<30$ & $26(1.5 \%)$ \\
\hline \multirow{3}{*}{ Albuminuria } & No albuminuria & $1456(83.6 \%)$ \\
\hline & $\begin{array}{l}\text { Microalbuminuria ( } \geq 2.5 \mathrm{mg} / \mathrm{mmol} \mathrm{M}, \geq 3.5 \mathrm{mg} / \mathrm{mmol} \mathrm{F} \\
\text { but }<30 \mathrm{mg} / \mathrm{mmol} \text { ) }\end{array}$ & $239(13.7 \%)$ \\
\hline & Macroalbuminuria ( $\geq 30$ mg/mmol) & $41(2.4 \%)$ \\
\hline \multirow{2}{*}{ Diabetes } & Yes & $294(16.9 \%)$ \\
\hline & No & $1447(83.1 \%)$ \\
\hline \multirow{3}{*}{ Hypertension } & On antihypertensive medication & $1426(81.9 \%)$ \\
\hline & $\begin{array}{l}\text { BP }>140 / 90 \text { at study assessment, but not on } \\
\text { antihypertensive medication }\end{array}$ & $102(5.9 \%)$ \\
\hline & No hypertension & $213(12.2 \%)$ \\
\hline \multirow{4}{*}{$\begin{array}{l}\text { Number of antihypertensive } \\
\text { medications }\end{array}$} & None & $315(18.1 \%)$ \\
\hline & 1 & $615(35.3 \%)$ \\
\hline & 2 & $488(28.0 \%)$ \\
\hline & 3 or more & $323(18.6 \%)$ \\
\hline \multirow{2}{*}{ Taking RAASi } & Yes & $1123(64.5 \%)$ \\
\hline & No & $618(35.5 \%)$ \\
\hline \multirow{2}{*}{ History of CVD } & Yes & $592(34.0 \%)$ \\
\hline & No & $1149(66.0 \%)$ \\
\hline \multirow{3}{*}{ Smoking } & Current & $81(4.7 \%)$ \\
\hline & Ex-smoker & $866(49.7 \%)$ \\
\hline & Never & $794(45.6 \%)$ \\
\hline
\end{tabular}


Table 1 Characteristics of people in the RRID study (Continued)

\begin{tabular}{|c|c|c|}
\hline & No alcohol & $711(40.8 \%)$ \\
\hline \multirow[t]{3}{*}{ Alcohol } & Drinking within recommended limits & $877(50.4 \%)$ \\
\hline & Drinking above recommended limits & $65(3.7 \%)$ \\
\hline & Normal or underweight & $353(20.3 \%)$ \\
\hline \multirow[t]{2}{*}{ BMI } & Overweight & $738(42.4 \%)$ \\
\hline & Obese & $650(37.3 \%)$ \\
\hline \multirow{2}{*}{ Central obesity } & Yes & $1480(85.0 \%)$ \\
\hline & No & $260(14.9 \%)$ \\
\hline Total chol:HDL ratio & $>4.5$ & $306(17.6 \%)$ \\
\hline \multirow{2}{*}{ Aware of CKD diagnosis } & Yes & $1026(58.9 \%)$ \\
\hline & No & $715(41.1 \%)$ \\
\hline
\end{tabular}

Abbreviations:

CKD chronic kidney disease.

BP blood pressure.

eGFR estimated Glomerular Filtration Rate.

GCSE General certificate of Secondary Education.

A level Advanced level.

NVQ National Vocational Qualification.

RAASi renin-angiotensin aldosterone system inhibitors.

CVD cardiovascular disease.

albuminuria, no diabetes with macroalbuminuria) were taking them. Among people taking only one agent $(\mathrm{n}=$ 615), 425 (69.1\%) were taking RAASi, 62 (10.1\%) were taking calcium channel blockers, 61 (9.9\%) were taking beta blockers, and 59 (9.6\%) were taking thiazide diuretics. Mean $( \pm$ SD) BP for people on antihypertensive agents was $134( \pm 18) / 72( \pm 11) \mathrm{mmHg}$. The NICE BP control target was achieved in $829 / 1426$ (58.1\%), the KDOQI target in $512 / 1426(35.9 \%)$, and the KDIGO target in $859 / 1426$ $(60.2 \%)$ (Table 2). BP control varied by diabetes status with $106 / 276$ (38.4\%) of people with diabetes achieving the NICE or KDOQI target (targets are the same in diabetes). 723/1150 (62.9\%), 407/1150 (35.3\%) and 695/1150 (60.4\%) of people without diabetes achieved the NICE, KDOQI, and KDIGO targets respectively (Table 2 and Figure 1). In both people with diabetes and without, optimal control was less likely in those with albuminuria (Chi-squared test for trend in non-diabetics $=7.68, \mathrm{p}=0.006$, and in diabetics $=8.59, \mathrm{p}=0.003)($ Figure 1$)$.

\section{Factors associated with suboptimal BP control}

On multivariable logistic regression analysis, older patients, those with diabetes, and those with albuminuria were less likely to achieve NICE BP targets whereas those with a history of cardiovascular disease were more likely to achieve them (Table 3). No difference was observed in these outcomes when CVD was excluded from the regression model. Findings for age and albuminuria were similar for KDOQI and KDIGO targets. The association with diabetes was not seen with either, but there was an association between lack of achievement of KDOQI target and male gender. All associations did not vary on sensitivity analysis in the population with eGFR $<60$ at baseline, with the exception of the loss of the gender association with KDOQI targets. No association was seen with socioeconomic status, ethnicity, awareness of CKD diagnosis, alcohol intake, BMI, central obesity, or taking NSAIDs (data not shown). There was also no association between number of agents and achievement of BP control by any of the targets (NICE $\mathrm{OR}=1.12(95 \%$ CI $0.88,1.43)$, KDOQI OR 1.02 (95\% CI $0.80,1.31)$, and KDIGO OR 1.05 (95\% CI 0.80,1.39)). Multivariable linear regression controlling for age, gender, albuminuria, previous CVD, and diabetes identified an association between number of antihypertensive drugs taken and lower MAP. For unit increase in number of antihypertensives, MAP dropped by $2.6 \mathrm{mmHg}$ ( $95 \% \mathrm{CI}$ 1.9,3.2, $\mathrm{p}<0.01$ ) (Figure 2). This effect was consistent when people with previous CVD were excluded from the analysis.

\section{Systolic and diastolic hypertension}

Of the 597 people not controlled below the NICE target, $435(72.9 \%)$ had isolated systolic hypertension $(\geq 140), 13$ $(2.2 \%)$ had isolated diastolic hypertension $(\geq 90)$, and 74 (12.4\%) had both systolic and diastolic hypertension. Table 4 shows the distribution of systolic and diastolic blood pressure by age and eGFR in the whole study population. Table 5 shows the variation in systolic and diastolic hypertension (despite treatment) by age, and demonstrates the predominance of systolic hypertension in older age groups. Logistic regression analysis of the associations of achieving NICE systolic and diastolic targets separately demonstrated that older people had a lower odds ratio of achieving systolic targets (OR 0.17 (95\% CI $0.09,0.32) \mathrm{p}<0.001$ for over 80 ), and greater odds ratio of 
Table 2 Blood pressure control by albuminuria and diabetes status among people on antihypertensive medication

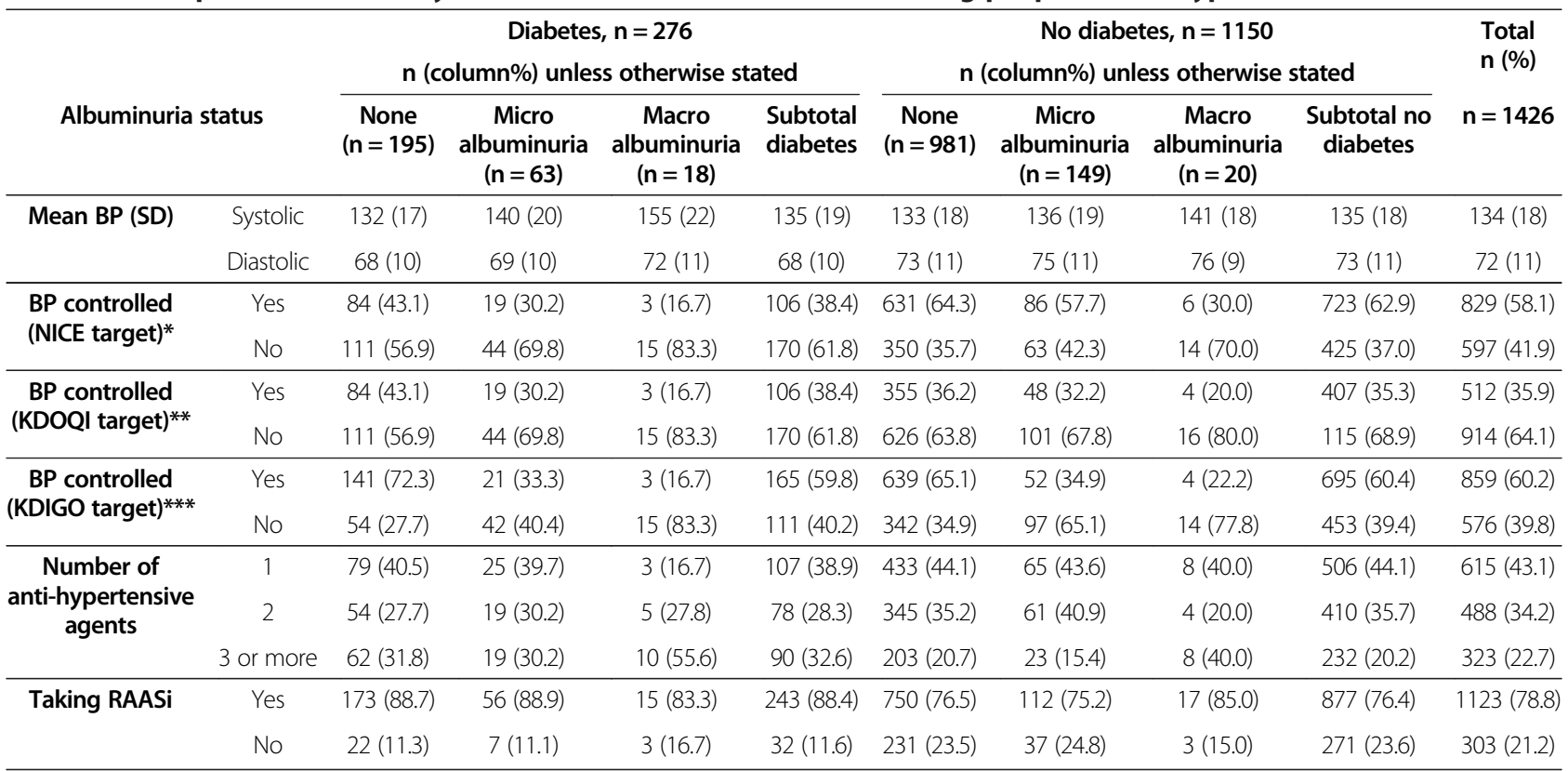

* $<140 / 90$ or $<130 / 80$ in people with diabetes and people with ACR $>70$.

$* * 130 / 80$ for all people with CKD.

*** $\leq 140 / 90$ or $130 / 80$ in people with albuminuria.

Microalbuminuria defined as $A C R>=2.5 \mathrm{mg} / \mathrm{mmol}$ (men), $>=3.5 \mathrm{mg} / \mathrm{mmol}$ (women) in at least two of the three urine specimens.

Macroalbuminuria defined as $A C R \geq 30 \mathrm{mg} / \mathrm{mmol}$.

Abbreviations:

BP blood pressure.

RAASi renin-angiotensin aldosterone system inhibitors.

NICE National Institute for Health and Clinical Excellence.

KDOQI National Kidney Foundation Kidney Disease Outcome Quality Initiative.

ACR albumin/creatinine ratio.

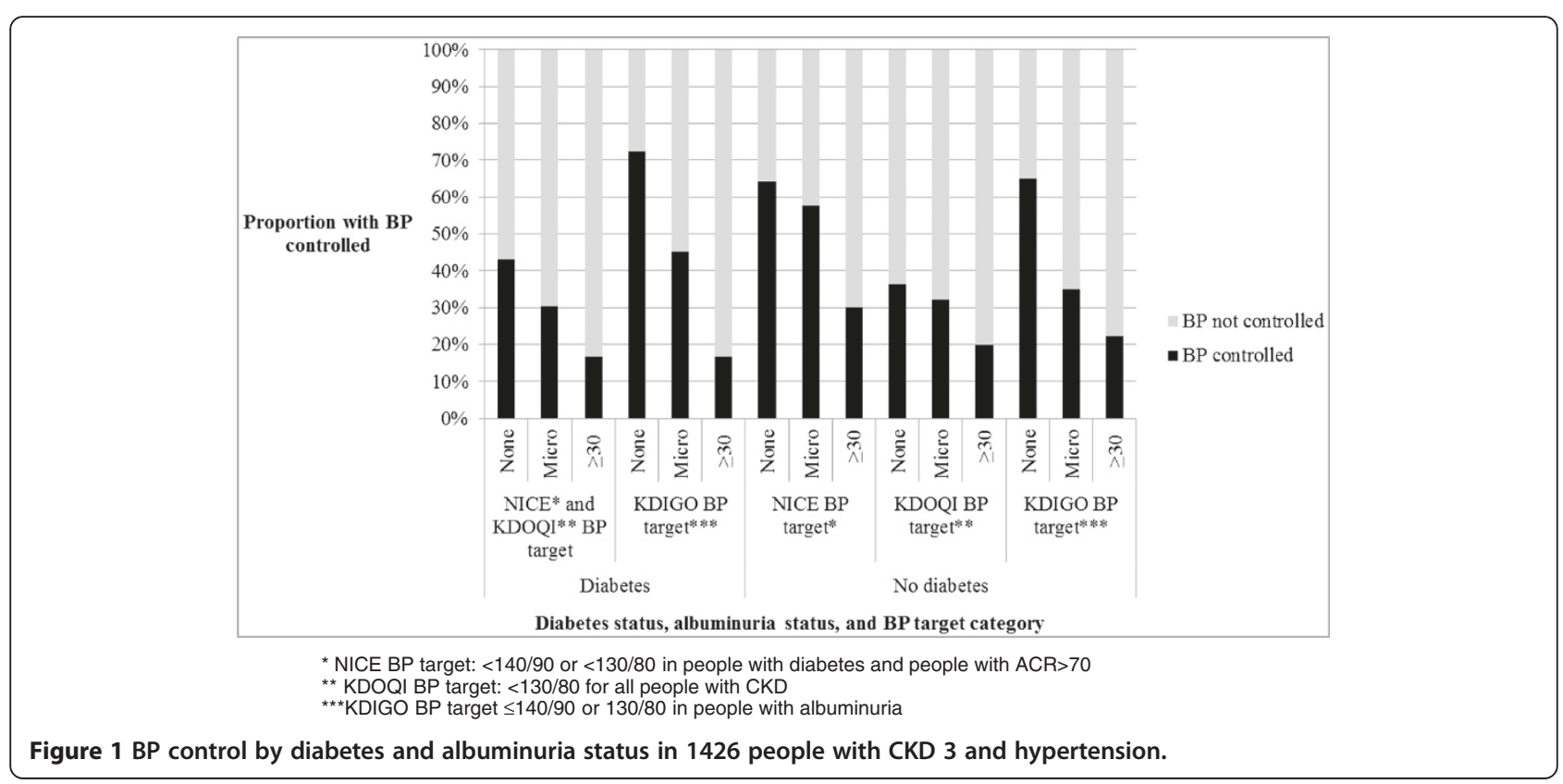


Table 3 Factors associated with achievement of BP targets in people on antihypertensive medication

\begin{tabular}{|c|c|c|c|c|c|c|c|c|c|c|c|c|c|}
\hline & & \multicolumn{2}{|c|}{$\begin{array}{l}\text { Univariate odds } \\
\text { ratios of achieving } \\
\text { NICE BP targets }\end{array}$} & \multicolumn{2}{|c|}{$\begin{array}{l}\text { Multivariable odds } \\
\text { ratios of achieving } \\
\text { NICE BP target } \infty\end{array}$} & \multicolumn{2}{|c|}{$\begin{array}{l}\text { Univariate odds } \\
\text { ratios of achieving } \\
\text { KDOQI BP targets }\end{array}$} & \multicolumn{2}{|c|}{$\begin{array}{l}\text { Multivariable odds } \\
\text { ratios of achieving } \\
\text { KDOQI BP target } \dagger\end{array}$} & \multicolumn{2}{|c|}{$\begin{array}{l}\text { Univariate odds } \\
\text { ratios of achieving } \\
\text { KDIGO BP targets }\end{array}$} & \multicolumn{2}{|c|}{$\begin{array}{l}\text { Multivariable odds } \\
\text { ratios of achieving } \\
\text { KDIGO BP target } \infty\end{array}$} \\
\hline & & OR $(95 \% \mathrm{Cl})$ & $\mathbf{p}$ & OR $(95 \% \mathrm{Cl})$ & $\mathbf{p}$ & OR $(95 \% \mathrm{Cl})$ & $\mathbf{p}$ & OR $(95 \% \mathrm{Cl})$ & $\mathrm{p}$ & OR $(95 \% \mathrm{Cl})$ & p & OR $(95 \% \mathrm{Cl})$ & $\mathbf{p}$ \\
\hline Sex (compared to female) & Male & $\begin{array}{c}0.91 \\
(0.73,1.12)\end{array}$ & 0.359 & $\begin{array}{c}0.88 \\
(0.71,1.10)\end{array}$ & 0.260 & $\begin{array}{c}0.80 \\
(0.64,1.00)\end{array}$ & 0.050 & $\begin{array}{c}0.76 \\
(0.60,0.96)\end{array}$ & 0.023 & $\begin{array}{c}0.75 \\
(0.61,0.93)\end{array}$ & 0.009 & $\begin{array}{c}0.93 \\
(0.74,1.18)\end{array}$ & 0.56 \\
\hline \multirow[t]{3}{*}{ Age (compared to $<60$ age group) } & $60-69$ & $\begin{array}{c}0.60 \\
(0.36,1.03)\end{array}$ & $<0.001$ & $\begin{array}{c}0.43 \\
(0.26,0.71)\end{array}$ & $<0.001$ & $\begin{array}{c}0.73 \\
(0.46,1.18)\end{array}$ & 0.155 & $\begin{array}{c}0.66 \\
(0.41,1.08)\end{array}$ & 0.002 & $\begin{array}{c}0.66 \\
(0.39,1.12)\end{array}$ & 0.001 & $\begin{array}{c}0.51 \\
(0.29,0.89)\end{array}$ & $<0.001$ \\
\hline & $70-79$ & $\begin{array}{c}0.43 \\
(0.26,0.71)\end{array}$ & & $\begin{array}{c}0.27 \\
(0.17,0.43)\end{array}$ & & $\begin{array}{c}0.64 \\
(0.41,1.01)\end{array}$ & & $\begin{array}{c}0.49 \\
(0.31,0.79)\end{array}$ & & $\begin{array}{c}0.52 \\
(0.32,0.87)\end{array}$ & & $\begin{array}{c}0.34 \\
(0.20,0.58)\end{array}$ & \\
\hline & $80+$ & $\begin{array}{c}0.35 \\
(0.21,0.59)\end{array}$ & & $\begin{array}{c}0.21 \\
(0.13,0.35)\end{array}$ & & $\begin{array}{c}0.60 \\
(0.38,0.97)\end{array}$ & & $\begin{array}{c}0.43 \\
(0.26,0.72)\end{array}$ & & $\begin{array}{c}0.41 \\
(0.24,0.68)\end{array}$ & & $\begin{array}{c}0.27 \\
(0.15,0.48)\end{array}$ & \\
\hline $\begin{array}{l}\text { Diabetes (compared to people } \\
\text { without diabetes) }\end{array}$ & $\begin{array}{l}\text { People with } \\
\text { diabetes }\end{array}$ & $\begin{array}{c}0.36 \\
(0.28,0.47) \\
\end{array}$ & $<0.001$ & $\begin{array}{c}0.32 \\
(0.25,0.43) \\
\end{array}$ & $<0.001$ & $\begin{array}{c}1.12 \\
(0.86,1.17) \\
\end{array}$ & 0.410 & $\begin{array}{c}1.08 \\
(0.81,1.43) \\
\end{array}$ & 0.601 & $\begin{array}{c}0.97 \\
(0.74,1.26) \\
\end{array}$ & 0.796 & $\begin{array}{c}1.14 \\
(0.85,1.53) \\
\end{array}$ & 0.38 \\
\hline Albuminuria (compared to no albuminuria) & $\begin{array}{l}\text { People with } \\
\text { albuminuria }\end{array}$ & $\begin{array}{c}0.54 \\
(0.41,0.72) \\
\end{array}$ & $<0.001$ & $\begin{array}{c}0.56 \\
(0.42,0.74) \\
\end{array}$ & 0.001 & $\begin{array}{c}0.70 \\
(0.52,0.95) \\
\end{array}$ & 0.021 & $\begin{array}{c}0.65 \\
(0.47,0.90) \\
\end{array}$ & 0.009 & $\begin{array}{c}0.70 \\
(0.52,0.95) \\
\end{array}$ & 0.021 & $\begin{array}{c}0.21 \\
(0.16,0.30) \\
\end{array}$ & $<0.001$ \\
\hline $\begin{array}{l}\text { History of CVD (compared to } \\
\text { people with no CVD) }\end{array}$ & $\begin{array}{l}\text { People with } \\
\text { CVD }\end{array}$ & $\begin{array}{c}1.41 \\
(1.13,1.76)\end{array}$ & 0.002 & $\begin{array}{c}1.87 \\
(1.49,2.35)\end{array}$ & $<0.001$ & $\begin{array}{c}1.66 \\
(1.33,2.07)\end{array}$ & $<0.001$ & $\begin{array}{c}1.89 \\
(1.49,2.39)\end{array}$ & $<0.001$ & $\begin{array}{c}1.42 \\
(1.14,1.77)\end{array}$ & 0.002 & $\begin{array}{c}1.83 \\
(1.43,2.34)\end{array}$ & $<0.001$ \\
\hline \multirow[t]{2}{*}{ eGFR (compared to 45-59) } & $60+$ & $\begin{array}{c}1.03 \\
(0.81,1.31)\end{array}$ & 0.001 & $\begin{array}{c}0.84 \\
(0.65,1.09)\end{array}$ & 0.088 & $\begin{array}{c}0.78 \\
(0.62,1.00)\end{array}$ & 0.145 & - & - & $\begin{array}{c}0.97 \\
(0.74,1.28)\end{array}$ & 0.004 & $\begin{array}{c}0.83 \\
(0.62,1.11)\end{array}$ & 0.27 \\
\hline & $<45$ & $\begin{array}{c}0.66 \\
(0.52,0.83)\end{array}$ & & $\begin{array}{c}0.77 \\
(0.60,0.99)\end{array}$ & & $\begin{array}{c}0.92 \\
(0.72,1.17)\end{array}$ & & & & $\begin{array}{c}0.66 \\
(0.52,0.85)\end{array}$ & & $\begin{array}{c}0.83 \\
(0.64,1.09)\end{array}$ & \\
\hline
\end{tabular}

$\infty$ Model adjusted for age, sex, albuminuria, diabetes, CVD, and eGFR

† Model adjusted for age, sex, albuminuria, diabetes, and CVD.

Abbreviations:

BP blood pressure.

RAASi renin-angiotensin aldosterone system inhibitors.

NICE National Institute for Health and Clinical Excellence.

KDOQI National Kidney Foundation Kidney Disease Outcome Quality Initiative.

CVD cardiovascular disease.

eGFR estimated Glomerular Filtration Rate. 


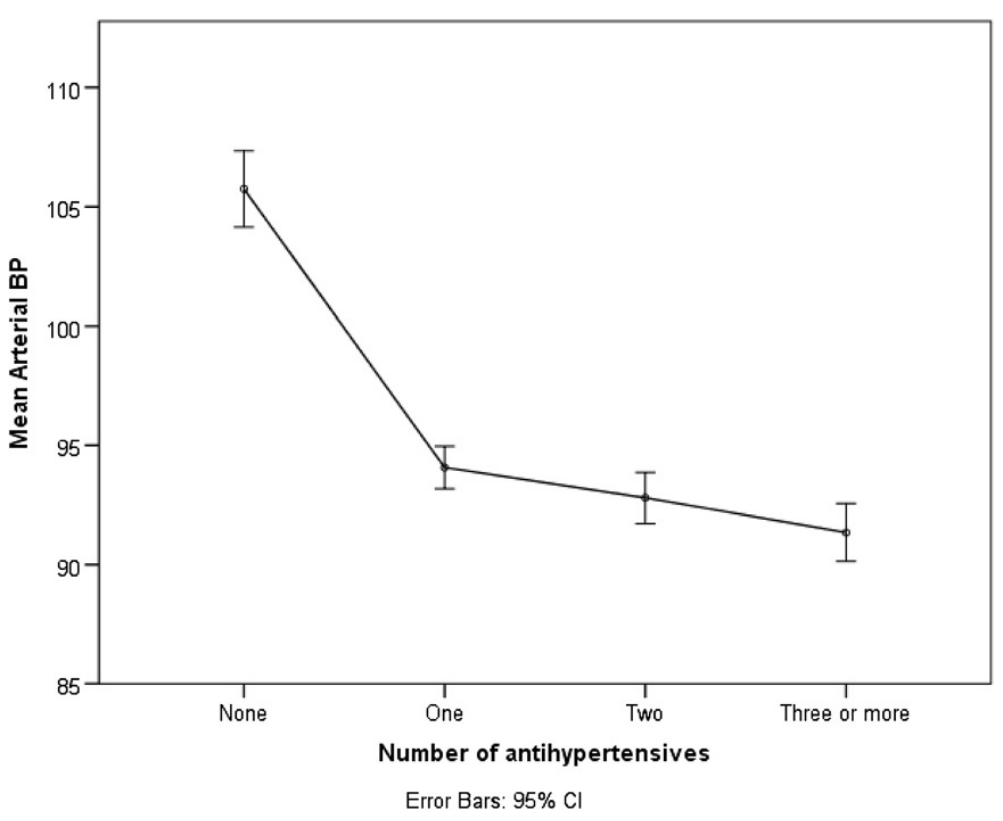

Figure 2 Number of antihypertensive medications and mean arterial BP in people with CKD 3 and hypertension.

achieving diastolic targets (OR 2.35 (95\% CI 1.11,4.96) $\mathrm{p}<0.001$ for over 80 ) compared to those under 60 years.

\section{Discussion}

In this cohort of 1741 people with CKD stage 3, hypertension was common with a prevalence of $88 \%$ and BP control was suboptimal, with $42 \%$ not achieving the NICE BP target, $40 \%$ not achieving the KDIGO BP target, and $64 \%$ not achieving the more strict KDOQI BP target. Presence of diabetes and higher levels of albuminuria were associated with a smaller proportion of people achieving BP control targets. After adjustment for potential confounding factors, poor BP control was associated with increasing age and albuminuria for all three BP target groups and with diabetes in the NICE BP target group. Older age was associated with better diastolic control and poorer systolic control. Better BP control was associated with past history of CVD. The majority of patients were on one or two antihypertensive medications (most commonly RAASi) and taking a greater number of antihypertensive medications was associated with lower MAP.

The prevalence of hypertension in this cohort is similar to other studies. In the Chronic Renal Insufficiency Cohort (CRIC) Study, it was between $82 \%$ and $91 \%$ in people with eGFR between 30 and $59 \mathrm{~mL} / \mathrm{min} / 1.73 \mathrm{~m}^{2}$ [33]. In the Kidney Early Evaluation Programme (KEEP) and the National Health and Nutrition Examination Survey (NHANES), the prevalence of hypertension was

Table 4 Variation in systolic and diastolic blood pressure by age and eGFR in whole study population

\begin{tabular}{|c|c|c|c|c|c|c|c|c|c|c|}
\hline & & & \multicolumn{8}{|c|}{ Age } \\
\hline & & & \multicolumn{2}{|c|}{$<60$} & \multicolumn{2}{|c|}{$60-69$} & \multicolumn{2}{|c|}{$70-79$} & \multicolumn{2}{|c|}{$80+$} \\
\hline & & & SBP & DBP & SBP & DBP & SBP & DBP & SBP & DBP \\
\hline & & & $\overline{\text { mean (SD) }}$ & $\overline{\text { mean }(\mathrm{SD})}$ & $\overline{\text { mean }(\mathrm{SD})}$ & $\overline{\text { mean }(\mathrm{SD})}$ & $\overline{\text { mean (SD) }}$ & $\overline{\text { mean }(\mathrm{SD})}$ & $\overline{\text { mean (SD) }}$ & $\overline{\text { mean (SD) }}$ \\
\hline & & & $\mathrm{mmHg}$ & $\mathrm{mmHg}$ & $\mathrm{mmHg}$ & $\mathrm{mmHg}$ & $\mathrm{mmHg}$ & $\mathrm{mmHg}$ & $\mathrm{mmHg}$ & $\mathrm{mmHg}$ \\
\hline \multirow[t]{8}{*}{ eGFR at baseline } & $>60$ & $\mathrm{n}$ & \multicolumn{2}{|c|}{40} & \multicolumn{2}{|c|}{148} & \multicolumn{2}{|c|}{174} & \multicolumn{2}{|c|}{56} \\
\hline & & $\overline{B P}$ & $122.1(15.0)$ & $78.7(9.8)$ & $131.8(15.6)$ & $77.3(10.0)$ & $136.2(16.6)$ & $73.9(9.8)$ & $139.0(19.3)$ & $75.1(10.9)$ \\
\hline & $45-59.99$ & $n$ & \multicolumn{2}{|c|}{68} & \multicolumn{2}{|c|}{231} & \multicolumn{2}{|c|}{412} & \multicolumn{2}{|c|}{200} \\
\hline & & $\mathrm{BP}$ & $124.2(15.6)$ & $77.6(10.1)$ & $130.7(16.4)$ & $74.7(11.1)$ & $134.3(16.6)$ & $71.8(10.6)$ & $138.4(21.4)$ & $70(11.1)$ \\
\hline & $30-44.99$ & $n$ & \multicolumn{2}{|c|}{19} & \multicolumn{2}{|c|}{63} & \multicolumn{2}{|c|}{164} & \multicolumn{2}{|c|}{140} \\
\hline & & $\mathrm{BP}$ & $125.5(22.1)$ & $79.3(12.73)$ & $133.8(17.4)$ & $74.7(11.8)$ & $135.0(21.0)$ & $69.0(10.7)$ & $137.5(20.7)$ & $69.2(11.1)$ \\
\hline & $<30$ & $n$ & \multicolumn{2}{|c|}{1} & \multicolumn{2}{|c|}{3} & \multicolumn{2}{|c|}{11} & \multicolumn{2}{|c|}{11} \\
\hline & & $\overline{B P}$ & 111.3 & 73.7 & $137.6(13.4)$ & $68(16.1)$ & $134.1(14.4)$ & $72.5(9.0)$ & $136.1(19.1)$ & $65.0(5.49)$ \\
\hline
\end{tabular}


Table 5 Variation in systolic and diastolic hypertension by age

\begin{tabular}{|c|c|c|c|c|c|c|}
\hline & & $\begin{array}{l}\text { Proportion with isolated } \\
\text { systolic hypertension } \\
\text { (SBP > 140) }\end{array}$ & $\begin{array}{l}\text { Proportion with isolated } \\
\text { diastolic hypertension } \\
\text { (DBP >90) }\end{array}$ & $\begin{array}{l}\text { Proportion with both systolic } \\
\text { and diastolic hypertension } \\
(\mathrm{SBP}>140 \text { and } \mathrm{DBP}>90)\end{array}$ & $\begin{array}{c}\text { Proportion with normal blood } \\
\text { pressure (both } \mathrm{SBP}<140 \\
\text { and DBP }<90 \text { ) }\end{array}$ & Total \\
\hline \multirow[t]{4}{*}{ Age group } & $<60$ & $7.8 \%$ & $4.7 \%$ & $7.0 \%$ & $80.5 \%$ & $100 \%$ \\
\hline & $60-69$ & $20.7 \%$ & $1.8 \%$ & $8.1 \%$ & $69.4 \%$ & $100 \%$ \\
\hline & $70-79$ & $32.9 \%$ & $0.7 \%$ & $3.7 \%$ & $62.8 \%$ & $100 \%$ \\
\hline & $80+$ & $39.8 \%$ & $0.2 \%$ & $4.2 \%$ & $55.8 \%$ & $100 \%$ \\
\hline
\end{tabular}

$\mathrm{SBP}=$ systolic blood pressure.

$\mathrm{DBP}=$ diastolic blood pressure

between 84 and $92 \%$ for people with eGFR between 40 and $60 \mathrm{~mL} / \mathrm{min} / 1.73 \mathrm{~m}^{2}[9,11]$. As with previous studies, systolic hypertension predominated in the uncontrolled group with hypertension [12]. The findings of poor BP control in older people, people with diabetes, and people with albuminuria are consistent with previous studies [9,31,32]. For the KDOQI target, we identified similar association with male gender identified in the Kidney Early Evaluation Program (KEEP) cohort, but not the association with obesity identified in KEEP $[9,15]$. The predominantly white population in this study limited our ability to draw conclusions about the association between CKD-related hypertension and ethnicity identified in other studies $[9,15,31,34]$. The main concern is that people at greater cardiovascular risk (older people and people with diabetes and/or albuminuria) and people at greater risk of progression (with diabetes and albuminuria) were less likely to achieve BP targets. In the UK in 2010/11, the mean practice-level achievement of the QOF target for blood pressure control in CKD patients was $74.9 \%$ (standard deviation (SD) $8.2 \%$ ), and the median $74.7 \%$ [23]. Our study has shown that BP control may be considerably worse than that when individual patient data are analysed and more robust targets are adopted $[19,21]$.

Recent data from the National Diabetes Audit in England showed that only $36.4 \%$ of people with diabetes were achieving target blood pressure $(<140 / 80$ if no comorbidity, <130/80 with comorbidity, including CKD) [35]. Our study findings are very similar $(38.0 \%$ of people with diabetes achieving BP targets) and add information on BP control by albuminuria status and in people without diabetes (Table 2).

There is evidence that RAAs inhibitors (RAASi) reduce progression of CKD in patients with diabetic nephropathy and in those with non-diabetic CKD and macroalbuminuria, [36,37] although a recent Cochrane review has not been able to identify sufficient evidence to determine the effectiveness of RAASi in patients with stage 1 to 3 CKD who do not have diabetes [38]. In the UK, NICE guidelines recommend offering RAASi to nondiabetic people with CKD and hypertension if they have macroalbuminuria $(A C R>=30 \mathrm{mg} / \mathrm{mmol}$ ), or to people with diabetic nephropathy who have ACR $>2.5 \mathrm{mg} / \mathrm{mmol}$ in men or $3 / 5 / \mathrm{mmol}$ in women [19]. RAASi were being taken by the majority of relevant participants in this study.

Despite not finding a significant association between numbers of hypertensive agents and achievement of optimal BP control, this study demonstrated that a large proportion of people were only taking one agent. Furthermore, there was an independent association between the number of antihypertensives and lower MAP, even when previous CVD was excluded (to remove indication bias). This suggests there is scope for improving BP control by the use of more antihypertensive agents in combination. The lack of association of agent number and optimal control may be as a result of indication bias, as many older patients have multiple co-morbidities. In recommendations to add more agents, risk of side effects, impact on quality of life, and costs all need to be considered, as well as issues of medication adherence. The potential for RAASi to precipitate acute kidney injury, for example, is an important factor requiring evaluation in this context. BP control and these related concerns will be important aspects for the proposed UK national CKD audit in primary care.

Optimal targets for BP control remain the subject of debate. Furthermore the correct management of isolated systolic hypertension is uncertain and very low blood pressure has been associated with poor outcomes, particularly in diabetes [39]. Further research would be valuable in the context of CKD. In this analysis we applied the two most widely applied evidence-based guidelines in use at the time that the study was conducted, NICE and KDOQI, and added analysis for the KDIGO guidelines in view of their current relevance.

This study had several strengths, including large numbers of people with CKD, being conducted in a primary care setting, standardisation of blood pressure and other measures, and the use of three morning urine samples to assess albuminuria. However, it also has several limitations, including its cross sectional design, which limits the ability to infer causality (although longitudinal follow up of this cohort will allow assessment of the effect of baseline BP on outcome, and of change in BP management on control). It is possible that people taking a single antihypertensive agent were taking it for other reasons, and that the observed relationship between CVD and improved BP 
control could be a reflection of reverse causality. We checked this among people with heart failure taking only one agent and identified only 25 people whose blood pressure was $<140 / 90$. We conclude that the risk of bias from people on single agents for reasons other than hypertension was therefore low. A further potential limitation is that a significant proportion of the study population (24\%) were found to have an eGFR $\geq 60$ at baseline, which might be considered to question their CKD diagnosis. However, all the participants met the formal definition for CKD prior to inclusion (including chronicity of low eGFR) and, importantly, were therefore on CKD registers in their respective GP practices. We therefore included them in the analyses to improve the generalisability of these findings to normal practice circumstances. There is also potential that non response to recruitment could have caused selection bias, and that the predominantly elderly population could result in survivor bias. The potential for selection bias means that caution should be used in application of these results to general populations with CKD. In addition, we cannot comment on whether people on antihypertensive treatment were receiving adequate doses of medication or adhering. Optimisation of drug dosage might therefore represent a potential area of improvement not assessed in this study. This study under-represents ethnic minorities and the findings should therefore be interpreted with caution in different ethnic groups. In addition, the study population is not representative of the general population due to the high proportion of older people. However, it included a range of general practices from urban and rural locations, and hence is broadly representative of people with CKD stage 3 in primary care in the UK. It therefore highlights the challenges of BP control, and the importance of measuring urine ACR and using it to guide intervention in patients with moderate CKD.

\section{Conclusions}

Failure to achieve BP targets was common in CKD patients with hypertension in this study, particularly in those at highest risk, and systolic hypertension predominated in those with uncontrolled BP. These findings suggest that there is scope for improving BP control in CKD stage 3 in primary care, possibly using more antihypertensive agents in combination, though there is a need to weigh potential side effects and costs.

\section{Additional file}

Additional file 1: Table S1. Characteristics of people with and without hypertension.

\section{Competing interests}

The authors declare that they have no financial or non financial competing interests.

\section{Authors' contributions}

SF designed and conducted the analyses and was the primary author. PR and MT helped to design the analyses and provided critical manuscript review. NM carried out the data collection and provided critical manuscript review. SH advised on statistical analyses. NM, CM, MT, and RF designed the RRID study and provided critical manuscript review. All authors read and approved the final manuscript.

\section{Acknowledgements}

This study was supported by a fellowship grant from Kidney Research UK and the British Renal Society, as well as an unrestricted educational grant from Roche Products plc.

The authors would also like to thank the collaborating GP practices and their staff.

\section{Author details}

'Academic Unit of Primary Care and Population Sciences, Faculty of Medicine, University of Southampton, South Academic Block, Southampton General Hospital, Tremona Road, Southampton, Hampshire SO16 6YD, UK.

${ }^{2}$ The Department of Renal Medicine, Royal Derby Hospital NHS Foundation Trust, Derby, Derbyshire, UK. ${ }^{3}$ School of Graduate Entry Health and Medicine, University of Nottingham, Nottingham, UK.

Received: 28 February 2013 Accepted: 17 June 2013

Published: 24 June 2013

\section{References}

1. Go AS, Chertow GM, Fan DJ, McCulloch CE, Hsu CY: Chronic kidney disease and the risks of death, cardiovascular events, and hospitalization. N Engl J Med 2004, 351(13):1296-1305.

2. Tangri N, Stevens LA, Griffith J, Tighiouart H, Djurdjev O, Naimark D, Levin A, Levey AS: A predictive model for progression of chronic kidney disease to kidney failure. JAMA 2011, 305(15):1553-1559.

3. Hallan S, Astor B, Romundstad S, Aasarod K, Kvenild K, Coresh J: Association of kidney function and albuminuria with cardiovascular mortality in older vs younger individuals - The HUNT II study. Arch Intern Med 2007, 167(22):2490-2496.

4. Matsushita K, van der Velde M, Astor BC, Woodward M, Levey AS, De Jong PE, Coresh J, Gansevoort RT, Chronic Kidney Disease Prognosis Consortium: Association of estimated glomerular filtration rate and albuminuria with all-cause and cardiovascular mortality in general population cohorts: a collaborative meta-analysis. Lancet 2010, 375(9731):2073-2081.

5. Warnock DG, Muntner P, McCullough PA, Zhang X, McClure LA, Zakai N, Cushman M, Newsome BB, Kewalramani R, Steffes MW, Howard G, McClellan WM, Regards Investigators: Kidney function, albuminuria, and all-cause mortality in the REGARDS (Reasons for Geographic and Racial Differences in Stroke) study. Am J Kidney Dis 2010, 56(5):861-871.

6. Arnlov J, Evans JC, Meigs JB, Wang TJ, Fox CS, Levy D, Benjamin EJ, D'Agostino RB, Vasan RS: Low-grade albuminuria and incidence of cardiovascular disease events in nonhypertensive and nondiabetic individuals - the Framingham heart study. Circulation 2005, 112(7):969-975.

7. Gerstein HC, Mann JF, Yi Q, Zinman B, Dinneen SF, Hoogwerf B, Halle JP, Young J, Rashkow A, Joyce C, Nawaz S, Yusuf S: Albuminuria and risk of cardiovascular events, death, and heart failure in diabetic and nondiabetic individuals. JAMA 2001, 286(4):421-426.

8. Hemmelgarn BR, Manns BJ, Lloyd A, James MT, Klarenbach S, Quinn RR, Wiebe N, Tonelli M, Alberta Kidney Disease Network: Relation between kidney function, proteinuria, and adverse outcomes. JAMA 2010, 303(5):423-429.

9. Kalaitzidis R, Li S, Wang C, Chen S-C, McCullough PA, Bakris GL: Hypertension in early-stage kidney disease: an update from the Kidney Early Evaluation Program (KEEP). Am J Kidney Dis 2009, 53(Suppl 4):S22-S31.

10. Collins AJ, Foley RN, Herzog C, Chavers B, Gilbertson D, Ishani A, Kasiske B, Liu J, Mau LW, McBean M, Murray A, St Peter W, Guo H, Gustafson S, Li Q, Li S, Li S, Peng Y, Qiu Y, Roberts T, Skeans M, Snyder J, Solid C, Wang C, Weinhandl E, Zaun D, Arko C, Chen SC, Dalleska F, Daniels F, et al: US Renal Data System 2010 Annual Data Report. Am J Kidney Dis 2011, 57(Suppl 1):A8, e1-526.

11. Coresh J, Wei GL, McQuillan G, Brancati FL, Levey AS, Jones C, Klag MJ: Prevalence of high blood pressure and elevated serum creatinine level in 
the United States: findings from the third National Health and Nutrition Examination Survey (1988-1994). Arch Intern Med 2001, 161(9):1207-1216.

12. Cheng L-T, Gao Y-L, Gu Y, Zhang L, Bi S-H, Tang W, Wang T: Stepwise increase in the prevalence of isolated systolic hypertension with the stages of chronic kidney disease. Nephrol Dial Transplant 2008, 23(12):3895-3900.

13. Parikh NI, Hwang S-J, Larson MG, Meigs JB, Levy D, Fox CS: Cardiovascular disease risk factors in chronic kidney disease - overall burden and rates of treatment and control. Arch Intern Med 2006, 166(17):1884-1891.

14. Muntner $\mathrm{P}, \mathrm{He}$ J, Astor BC, Folsom AR, Coresh J: Traditional and nontraditional risk factors predict coronary heart disease in chronic kidney disease: results from the Atherosclerosis Risk in Communities study. J Am Soc Nephrol 2005, 16(2):529-538.

15. Sarafidis PA, Li S, Chen SC, Collins AJ, Brown WW, Klag MJ, Bakris GL: Hypertension awareness, treatment, and control in chronic kidney disease. Am J Med 2008, 121(4):332-340.

16. Altun B, Suleymanlar G, Utas C, Arinsoy T, Ates K, Ecder T, Camsari T, Serdengecti K: Prevalence, awareness, treatment and control of hypertension in adults with chronic kidney disease in turkey: results from the CREDIT study. Kidney Blood Press Res 2012, 36:36-46.

17. Martinez-Castelao A, Gorriz JL, Portoles JM, De Alvaro F, Cases A, Luno J, Navarro-Gonzalez JF, Montes R, De la Cruz-Troca JJ, Natarajan A, Batlle D: Baseline characteristics of patients with chronic kidney disease stage 3 and stage 4 in spain: the MERENA observational cohort study. BMC Nephrol 2011, 12:53.

18. NHS Employers and British Medical Association: Quality and Outcomes Framework guidance for GMS contract 2011/12. Delivering investment in general practice. Leeds; 2011.

19. National Institute for Health and Clinical Excellence: Guideline 73: Chronic Kidney disease. Early identification and management of chronic kidney disease in adults in primary and secondary care. London; 2008.

20. The Health and Social Care Information Centre: Indicators for quality improvement; full indicator list. London; 2009

21. Kidney Disease Outcomes Quality Initiative (K/DOQI): K/DOQI clinical practice guidelines on hypertension and antihypertensive agents in chronic kidney disease. Am J Kidney Dis 2004, 43(Suppl 1):1-290.

22. Kidney Disease: Improving Global Outcomes (KDIGO) Blood Pressure Work Group: KDIGO Clinical practice guideline for the management of blood pressure in chronic kidney disease. Kidney Int Supp/ 2012, 2(5):337-414.

23. Stevens PE, De Lusignan S, Farmer CK, Tomson CR: Engaging primary care in CKD initiatives: the UK experience. Nephrol Dial Transplant 2012, 27(Suppl 3):S5-S11.

24. Mclntyre NJ, Fluck RJ, Mclntyre CW, Taal MW: Skin autofluorescence and the association with renal and cardiovascular risk factors in Chronic Kidney Disease stage 3. Clin J Am Soc Nephrol 2011, 6(10):2356-2363.

25. Jordan H, Roderick P, Martin D: The Index of Multiple Deprivation 2000 and accessibility effects on health. J Epidemio/ Community Health 2004, 58(3):250-257

26. Grundy E, Holt G: The socioeconomic status of older adults: how should we measure it in studies of health inequalities? J Epidemiol Community Health 2001, 55(12):895-904.

27. Levey AS, Coresh J, Greene T, Stevens LA, Zhang YL, Hendriksen S, Kusek JW, Van Lente F: Using standardized serum creatinine values in the modification of diet in renal disease study equation for estimating glomerular filtration rate. Ann Intern Med 2006, 145(4):247-254

28. The World Health Organisation Global Database on Body Mass Index: ; 2012. [http://apps.who.int/bmi/index.jsp?introPage=intro 3.html].

29. Pinto-Sietsma SJ, Navis G, Janssen WMT, De Zeeuw D, Gans R̈OB, De Jong PE, Grp PS: A central body fat distribution is related to renal function impairment, even in lean subjects. Am J Kidney Dis 2003, 41(4):733-741.

30. World Health Organization: The Definition and Diagnosis of Diabetes Mellitus and Intermediate Glycaemia. Geneva; 2006.

31. Chobanian AV, Bakris GL, Black HR, Cushman WC, Green LA, Izzo JL Jr, Jones DW, Materson BJ, Oparil S, Wright JT Jr, Roccella EJ: The Seventh Report of the Joint National Committee on Prevention, Detection, Evaluation, and Treatment of High Blood Pressure: the JNC 7 report. JAMA 2003, 289(19):2560-2572

32. Yang X, Ko GT, So WY, Ma RC, Kong AP, Lam CW, Ho CS, Chow CC, Tong PC, Chan JC: Additive interaction of hyperglycemia and albuminuria on risk of ischemic stroke in type 2 diabetes: Hong Kong Diabetes Registry. Diabetes Care 2008, 31(12):2294-2300.
33. Muntner P, Anderson A, Charleston J, Chen Z, Ford V, Makos G, O'Connor A, Perumal K, Rahman M, Steigerwalt S, Teal V, Townsend R, Weir M, Wright JT Jr, Investigators CS: Hypertension awareness, treatment, and control in adults with CKD: results from the Chronic Renal Insufficiency Cohort (CRIC) Study. Am J Kidney Dis 2010, 55(3):441-451.

34. Hull S, Dreyer G, Badrick E, Chesser A, Yaqoob MM: The relationship of ethnicity to the prevalence and management of hypertension and associated chronic kidney disease. BMC Nephrol 2011, 12:41.

35. National Diabetes Audit 2010-2011: Report 1: Care processes and treatment targets. Health and Social Care Information Centre; 2012. Available at: [http://www.ic.nhs.uk/searchcatalogue?productid $=7331 \& q=\% 22$ National +diabetes+audit\%22\&sort=Relevance\&size $=10 \&$ page $=1$ \#top] Last accessed January 2013.

36. Strippoli GFM, Craig M, Deeks JJ, Schena FP, Craig JC: Effects of angiotensin converting enzyme inhibitors and angiotensin II receptor antagonists on mortality and renal outcomes in diabetic nephropathy: systematic review. BMJ 2004, 329(7470):828-831.

37. Jafar TH, Stark PC, Schmid CH, Landa M, Maschio G, De Jong PE, De Zeeuw D, Shahinfar S, Toto R, Levey AS, Grp AS: Progression of chronic kidney disease: the role of blood pressure control, proteinuria, and angiotensin-converting enzyme inhibition - a patient-level meta-analysis. Ann Intern Med 2003, 139(4):244-252

38. Sharma P, Blackburn RC, Parke CL, McCullough $\mathrm{K}$, Marks A, Black C: Angiotensin-converting enzyme inhibitors and angiotensin receptor blockers for adults with early (stage 1 to 3 ) non-diabetic chronic kidney disease. Cochrane Database Syst Rev 2011(10):CD007751.

39. Vamos EP, Harris M, Millett C, Pape UJ, Khunti K, Curcin V, Molokhia M, Majeed A: Association of systolic and diastolic blood pressure and all cause mortality in people with newly diagnosed type 2 diabetes: retrospective cohort study. BMJ 2012, 345:e5567. doi: 10.1136/bmj.e5567.

\section{doi:10.1186/1471-2296-14-88}

Cite this article as: Fraser et al:: Suboptimal blood pressure control in chronic kidney disease stage 3: baseline data from a cohort study in primary care. BMC Family Practice 2013 14:88.

\section{Submit your next manuscript to BioMed Central and take full advantage of:}

- Convenient online submission

- Thorough peer review

- No space constraints or color figure charges

- Immediate publication on acceptance

- Inclusion in PubMed, CAS, Scopus and Google Scholar

- Research which is freely available for redistribution

Submit your manuscript at www.biomedcentral.com/submit
C) Biomed Central 